\title{
Prototype Switching Proyektor Wireless Berbasis Web dengan Virtual Network Computing (VNC) Server Menggunakan Raspberry Pi 3
}

\author{
Riza Samsinar ${ }^{1}$, Sulistiawan ${ }^{2}$ \\ 1) 2) Teknik Elektro Universitas Muhammadiyah Jakarta \\ Jl. Cempaka Putih Tengah 27 \\ Email: ${ }^{1)}$ riza.samsinar@ftumj.ac.id , 2) 2012420028@ftumj.ac.id
}

\begin{abstract}
ABSTRAK
Pada perangkat wireless ini berfungsi untuk memudahkan pengguna menghubungkan komputer atau laptop ke projector. Biasanya pengguna masih menggunakan kabel penghubung diantara komputer atau laptop ke projector. Penggunaan perangkat wireless ini memiliki jangkuan luas untuk pengguna. Penggunaan perangkat wireless ini dapat digunakan pada ruangan terbuka. Jangkauan yang dapat diakses oleh pengguna hingga 6 Meter. Dalam menggunakan perangkat wireless ini pengguna perlu menginstal driver software agar dapat digunakan. Software tersebut berfungsi sebagai perintah agar terkoneksi pada perangkat wireless sesuai yang diharapkan. Jika pengguna ingin menghubungkan ke perangkat wireless harus mempunyai Wi-Fi pada komputer atau laptop. Mini PC Raspberry pi 3 model B+ ini berfungsi sebagai pemproses perintah yang dilakukan oleh pengguna. Penggunaan keseluruhan pengguna mengakses melalui internet pada modem dengan security key didalamnya, kemudian membuka browser untuk mengkoneksikannya. Dalam penggunaan perangkat wireless ini pengguna yang telah terhubung dan diijinkan oleh admin akan tampil pada layar projector.
\end{abstract}

\section{Kata kunci : VNC, Raspberry pi, wi-fi, Web server}

\begin{abstract}
This wireless device functions to make it easier for users to connect a computer or laptop to the projector. Usually users still use the connecting cable between the computer or laptop to the projector. The use of this wireless device has a wide reach for users. The use of this wireless device can be used in an open space. The user-accessible range is up to 6 meters. In using this wireless device the user needs to install a software driver so that it can be used. The software functions as an order to connect to a wireless device as expected. If users want to connect to a wireless device, they must have Wi-Fi on their computer or laptop. This Raspberry pi 3 model B + mini PC functions as a processing command carried out by the user. The whole user accesses via the internet on a modem with a security key in it, then opens a browser to connect to it. In using this wireless device, users who have been connected and allowed by the admin will appear on the projector screen.
\end{abstract}

Keywords: VNC, Raspberry pi, wi-fi, Web server

\section{PENDAHULUAN}

Saat ini pertumbuhan teknologi berkembang begitu pesat, berbagai macam teknologi dengan penuh inovasi banyak bermunculan secara terus menerus. Semua diciptakan semata-mata untuk mempermudah manusia menjalani kegiatan dalam kehidupan sehari-hari. Pada saat ini, presentasi didepan umum dengan menggunakan proyektor masih dilakukan dengan cara konvensional, yaitu dengan menghubungkan kabel dari proyektor ke perangkat komputer laptop. Dengan cara seperti ini masih sangat merepotkan dikala perangkat komputer harus berpindah dari satu tempat ke tempat lainnya, begitupun saat ingin bertukar perangkat (laptop) dari satu ke yang lainnya. Sebuah sistem kontol perangkat-perangkat listrik jarak jauh digunakan untuk memudahkan pengguna dalam mengoperasikan atau memonitornya dari tempat yang jauh [1]. Dengan kemajuan masyarakat dan rumah pintar, permintaan peralatan rumah tangga semakin meningkat yang mengakibatkan peningkatan kendali jarak jauh untuk mereka [2]. Saat ini pertumbuhan teknologi berkembang dengan pesat, berbagai macam teknologi dengan penuh inovasi [3]. Seiring berkembangnya zaman, sistem komunikasi nirkabel kini telah berkembang pada perangkat elektronika [4]. Jaringan area lokal nirkabel (WLAN) telah berkembang biak di seluruh dunia dan digunakan dalam industri, di pemerintah, dan di rumah. [5]. Raspberry Pi memiliki kelebihan untuk system kendali [6]. Di sebagian besar peralatan elektronik konsumen dan hiburan, dari camcorder hingga peralatan stereo, remote control inframerah biasanya selalu disertakan. [7]. Saat ini proyektor dengan 
RESISTOR (Elektronika Kendali Telekomunikasi Tenaga Listrik Komputer) Vol. 3 No. 2 e-ISSN : 2621-9700, p-ISSN : 2654-2684

teknologi wireless sudah banyak ditemukan dipasaran, namun harga yang relatif mahal masih menjadi pertimbangan disebagian pengguna. Dengan harga yang cukup mahal tersebut, pengguna diberikan kemudahan ketika melakukan presentasi, yaitu dengan teknologi jaringan wireless yang dapat menghubungkan suatu perangkat tanpa menggunakan kabel penghubung dari laptop ke proyektor. Dengan menggunakan wireless network memudahkan untuk melakukan presentasi tanpa harus terhubung dengan kabel, sehingga dengan leluasa serta nyaman ketika presentasi. Output penelitian tersebut merancang suatu wireless proyektor dengan system wireless menggunakan raspberry menggunakan Virtual Network Computing (VNC) supaya tanpa harus menggunakan kabel penghubung antara proyektor dengan laptop dan mampu menampung lebih dari satu laptop dengan metode switch pada server.

\section{PERANCANGAN SISTEM}

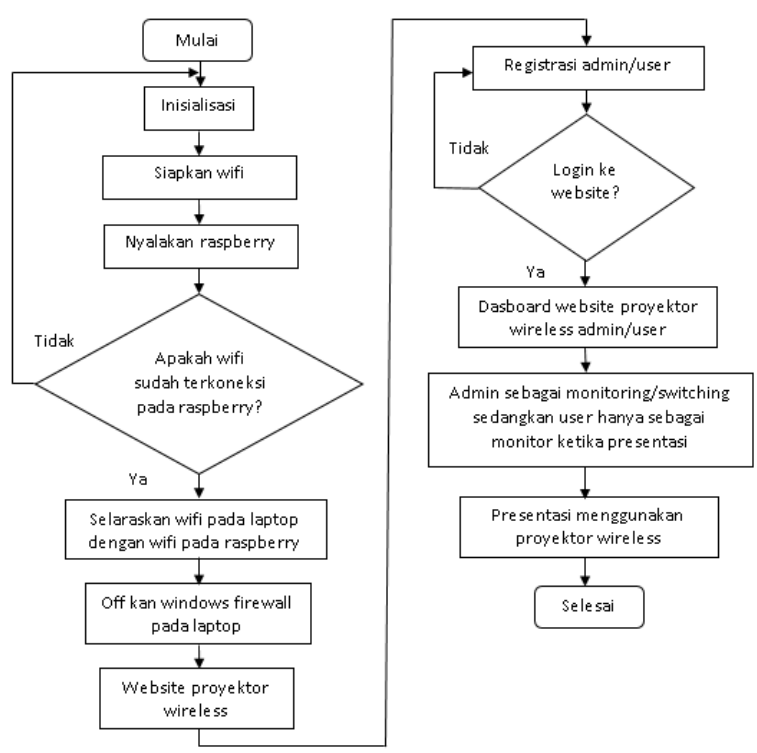

Gambar 1 Flowchart projector wireless.

Fungsi flowchart system ini sebagai system projector wireless, system ini bekerja apabila dapat inputan dengan wifi. Raspberry pi terhubung supaya bisa komunikasi dengan user laptop nya supaya bisa presentasi tanpa melalui media kabel tetapi media wireless. Laptop akan connect dengan website apabila windows firewall dalam posisi off. Kemudian scan IP laptop untuk dijadikan user maupun admin. Setelah itu buat registrasi supaya laptop user/admin interface terhadap laptop dengan perangkat lunak terhubung dengan wireless. User hanya sebagai untuk monitoring untuk presentasi materi, sedangkan admin bisa mengatur siapa saja yang mau presentasi tersebut. Ketika semua sudah akses maka akan bisa presentasi melalui wireless. Website ini juga dapat mengupload dan mendowload file presentasi.

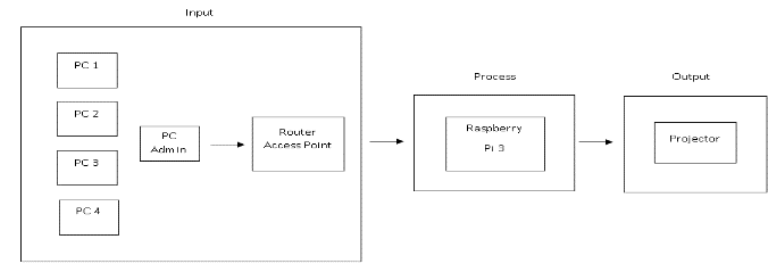

Gambar 2 Blok diagram.

Pada umumnya cara kerja sistem perangkat projector nirkabel yang berasal dari pengguna (user) menggunakan laptop atau komputer yang terdapat Wi-Finya untuk menghubungkan ke modul Wi-Fi yang sudah terhubung ke mini PC. Setelah terhubung maka digunakan sebuah software yang berfungsi sebagai perintah yang akan digunakan untuk memerintah "terkoneksi” dan "tidak terkoneksi” pada projector yang ingin digunakan.

Dapat disimpulkan bahwa pada blok diagram diatas terdiri atas tiga bagian yaitu proses masukan (input) pada pengguna (user) menggunakan komputer/laptop yang terdapat Wi-Fi sebagai media penghubung ke bagian proses (process). proses (process) terdapat Modul Wi-Fi yang terhubung ke mini PC yang berfungsi sebagai perintah terkoneksi atau tidak pada keluaran (output). Keluaran (output) yang digunakan yaitu projector.

PROSEDUR PERSIAPAN PERANCANGAN PROJECTOR WIRELESS

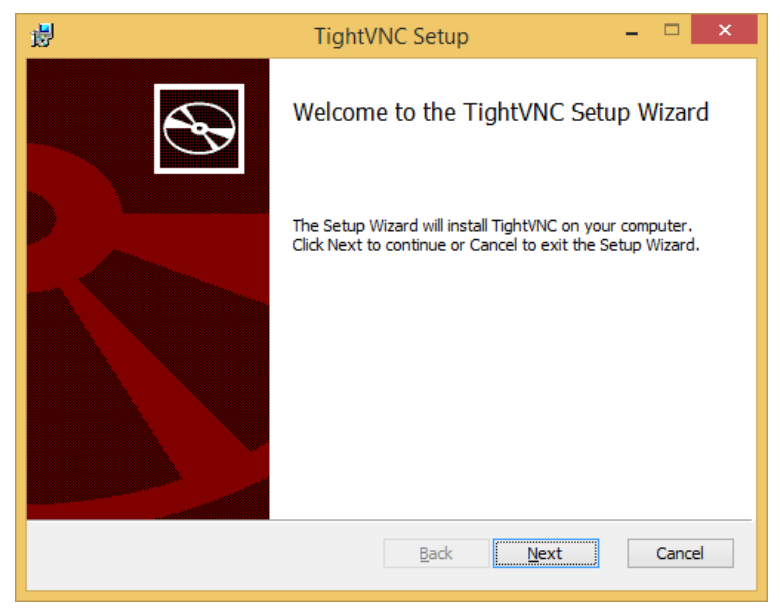

Gambar 3 Install Tight VNC. 
RESISTOR (Elektronika Kendali Telekomunikasi Tenaga Listrik Komputer) Vol. 3 No. 2 e-ISSN : 2621-9700, p-ISSN : 2654-2684

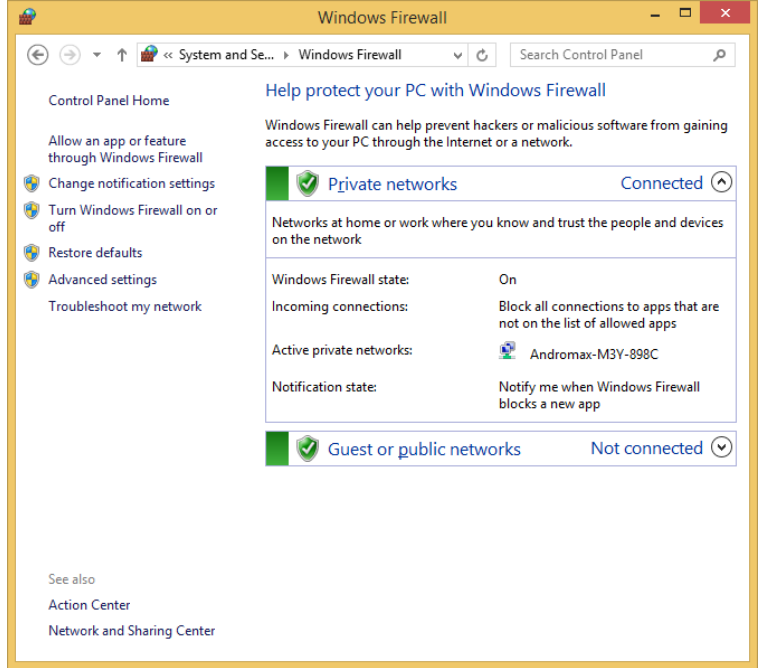

Gambar 4 Nonaktifkan Windows Firewall.

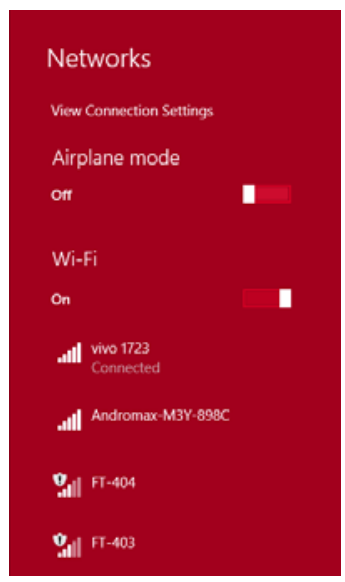

Gambar 5 Status Connect wi-fi terhubung.

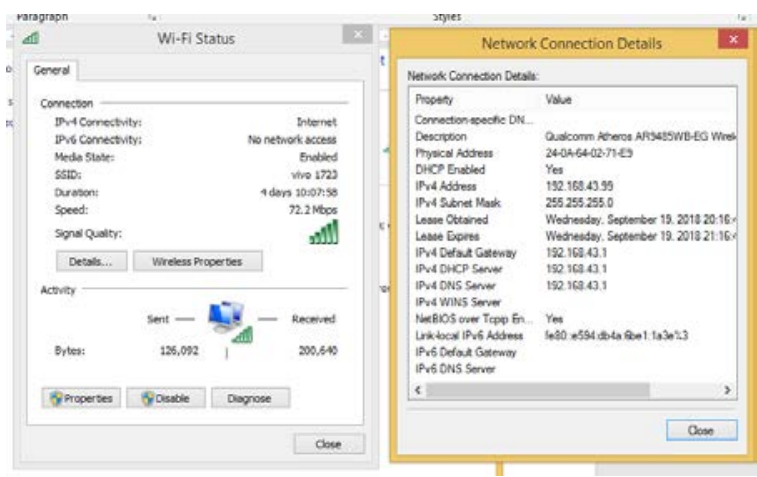

Gambar 6 Scan IP Laptop untuk dihubungkan melalui website.

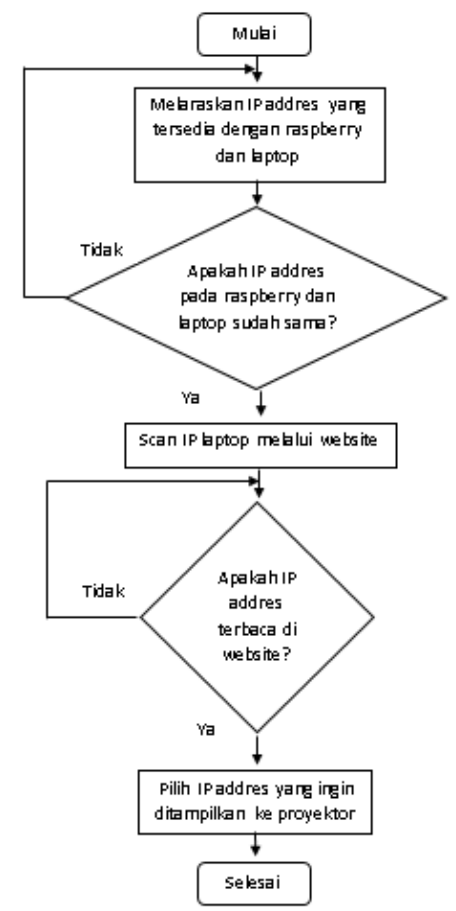

Gambar 7 Flowchart perangkat lunak.

3 PEMBAHASAN DAN HASIL PENGUJIAN PERANGKAT LUNAK

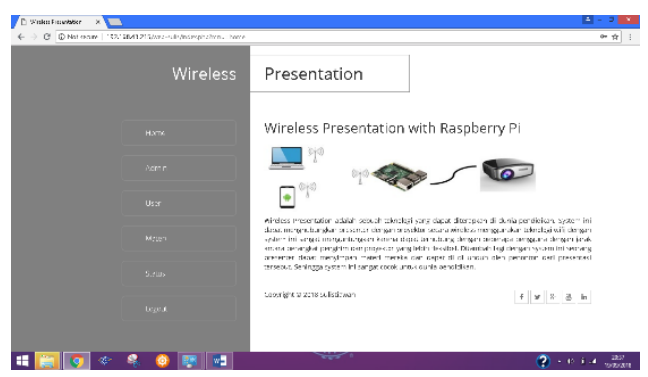

Gambar 8 Menu dashboard website projector wireless.

\section{PENGUJIAN JARAK PROJECTOR WIRELESS}

Tabel 1 Pengujian jarak projector wireless.

\begin{tabular}{|c|c|c|c|}
\hline No & Jarak & Terdeteksi & Tidak Terdeteksi \\
\hline 1. & 2 Meter & Ya & - \\
\hline 2. & 4 Meter & Ya & - \\
\hline 3. & 6 Meter & Ya & - \\
\hline 4. & 8 Meter & - & Ya \\
\hline 5. & 10 Meter & - & Ya \\
\hline
\end{tabular}

Dari data table diatas bahwa projector wireless bekerja dengan jarak maksimal 6 meter terhadap 
RESISTOR (Elektronika Kendali Telekomunikasi Tenaga Listrik Komputer) Vol. 3 No. 2 e-ISSN : 2621-9700, p-ISSN : 2654-2684

internet. Jika memasuki jarak 8 Meter dan 10 meter maka tidak terdeteksi dikarenakan jangkauan wi-fi tidak bisa diterima oleh projector wireless tersebut.

\section{PENGUJIAN 2 LAPTOP YANG BERBEDA SECARA BERSAMAAN}

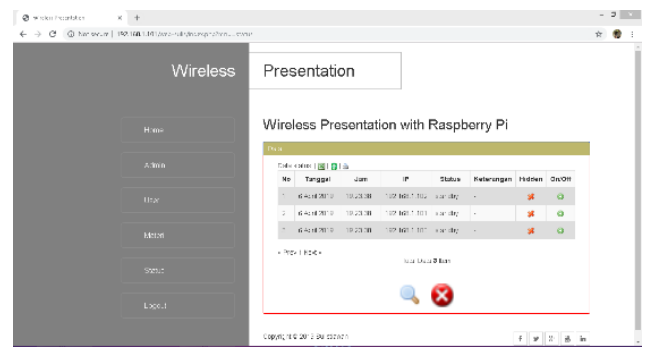

Gambar 9 Hasil pengujian.

Tabel 2 Pengujian secara bersamaan.

\begin{tabular}{|c|c|c|c|}
\hline No. & Laptop ke-1 & Laptop ke-2 & $\begin{array}{c}\text { Terhubung ke } \\
\text { perangkat }\end{array}$ \\
\hline 1. & \multirow{5}{*}{$\begin{array}{l}\text { Klik } \\
\text { "ON" }\end{array}$} & \multirow{5}{*}{$\begin{array}{l}\text { Klik } \\
\text { "ON" }\end{array}$} & Pengguna ke- 2 \\
\hline 2. & & & Pengguna ke- 2 \\
\hline 3. & & & Pengguna ke-1 \\
\hline 4. & & & Pengguna ke-1 \\
\hline 5. & & & Pengguna ke- 2 \\
\hline
\end{tabular}

PENGUJIAN DATA TEXT

Tabel 3 Pengujian text.

\begin{tabular}{|c|c|c|c|c|c|c|}
\hline \multirow{2}{*}{ Jarak } & \multicolumn{3}{|c|}{ Percobaan ke-1 } & \multicolumn{3}{c|}{ Percobaan ke-2 } \\
\cline { 2 - 7 } & Unduh & Unggah & $\begin{array}{c}\text { Total } \\
\text { Data }\end{array}$ & Unduh & Unggah & $\begin{array}{c}\text { Total } \\
\text { Data }\end{array}$ \\
\hline 2 Meter & $1.45 \mathrm{~KB} / \mathrm{s}$ & $11.5 \mathrm{~KB} / \mathrm{s}$ & $64.6 \mathrm{~KB}$ & $1.36 \mathrm{~KB} / \mathrm{s}$ & $11.4 \mathrm{~KB} / \mathrm{s}$ & $63.6 \mathrm{~KB}$ \\
\hline 4 Meter & $3.97 \mathrm{~KB} / \mathrm{s}$ & $19,3 \mathrm{~KB} / \mathrm{s}$ & $116 \mathrm{~KB}$ & $2.86 \mathrm{~KB} / \mathrm{s}$ & $19.6 \mathrm{~KB} / \mathrm{s}$ & $112 \mathrm{~KB}$ \\
\hline 6 Meter & $5.75 \mathrm{~KB} / \mathrm{s}$ & $36.7 \mathrm{~KB} / \mathrm{s}$ & $212 \mathrm{~KB}$ & $5.46 \mathrm{~KB} / \mathrm{s}$ & $36.6 \mathrm{~KB} / \mathrm{s}$ & $210 \mathrm{~KB}$ \\
\hline 8 Meter & $0 \mathrm{~KB} / \mathrm{s}$ & $0 \mathrm{~KB} / \mathrm{s}$ & $0 \mathrm{~KB} / \mathrm{s}$ & $0 \mathrm{~KB} / \mathrm{s}$ & $0 \mathrm{~KB} / \mathrm{s}$ & $0 \mathrm{~KB} / \mathrm{s}$ \\
\hline 10 Meter & $0 \mathrm{~KB} / \mathrm{s}$ & $0 \mathrm{~KB} / \mathrm{s}$ & $0 \mathrm{~KB} / \mathrm{s}$ & $0 \mathrm{~KB} / \mathrm{s}$ & $0 \mathrm{~KB} / \mathrm{s}$ & $0 \mathrm{~KB} / \mathrm{s}$ \\
\hline
\end{tabular}

\section{PENGUJIAN DATA GAMBAR}

Tabel 4 Pengujian data gambar.

\begin{tabular}{|c|c|c|c|c|c|c|}
\hline \multirow{2}{*}{ Jarak } & \multicolumn{3}{|c|}{ Percobaan ke-1 } & \multicolumn{3}{|c|}{ Percobaan ke-2 } \\
\cline { 2 - 7 } & Unduh & Unggah & $\begin{array}{c}\text { Total } \\
\text { Data }\end{array}$ & Unduh & Unggah & $\begin{array}{c}\text { Total } \\
\text { Data }\end{array}$ \\
\hline 2 Meter & $2.43 \mathrm{~KB} / \mathrm{s}$ & $41.9 \mathrm{~KB} / \mathrm{s}$ & $222 \mathrm{~KB}$ & $4.45 \mathrm{~KB} / \mathrm{s}$ & $41.2 \mathrm{~KB} / \mathrm{s}$ & $228 \mathrm{~KB}$ \\
\hline 4 Meter & $4.60 \mathrm{~KB} / \mathrm{s}$ & $60.7 \mathrm{~KB} / \mathrm{s}$ & $326 \mathrm{~KB}$ & $5.29 \mathrm{~KB} / \mathrm{s}$ & $60.0 \mathrm{~KB} / \mathrm{s}$ & $326 \mathrm{~KB}$ \\
\hline 6 Meter & $6.88 \mathrm{~KB} / \mathrm{s}$ & $76.5 \mathrm{~KB} / \mathrm{s}$ & $417 \mathrm{~KB}$ & $5.78 \mathrm{~KB} / \mathrm{s}$ & $76.9 \mathrm{~KB} / \mathrm{s}$ & $413 \mathrm{~KB}$ \\
\hline 8 Meter & $0 \mathrm{~KB} / \mathrm{s}$ & $0 \mathrm{~KB} / \mathrm{s}$ & $0 \mathrm{~KB} / \mathrm{s}$ & $0 \mathrm{~KB} / \mathrm{s}$ & $0 \mathrm{~KB} / \mathrm{s}$ & $0 \mathrm{~KB} / \mathrm{s}$ \\
\hline 10 Meter & $0 \mathrm{~KB} / \mathrm{s}$ & $0 \mathrm{~KB} / \mathrm{s}$ & $0 \mathrm{~KB} / \mathrm{s}$ & $0 \mathrm{~KB} / \mathrm{s}$ & $0 \mathrm{~KB} / \mathrm{s}$ & $0 \mathrm{~KB} / \mathrm{s}$ \\
\hline
\end{tabular}

\section{KESIMPULAN}

1. Berhasilnya pengguna perangkat wireless sebagai pengganti media kabel yang terhubung antara laptop atau computer ke projector. Penggunaan jarak 2 Meter sampai dengan 6 Meter masih terdeteksi oleh jangkauan wireless. Sedangkan lebih dari 6 Meter maka perangkat projector wireless tidak terdeteksi.

2. Penggunaan perangkat projector wireless ini hanya bisa digunakan untuk menampilkan slide berbetentuk teks/gambar.

3. Banyaknya perangkat yang terhubung tergantung pada modul wifi yang dipergunakan, semakin baik modul wifi semakin banyak perangkat yang bisa terhubung ke web server.

\section{DAFTAR PUSTAKA}

[1] S. Bahri and A. Sudrajat, "Rancang Bangun Prototype Sistem Kontrol Jarak Jauh Berbasis Ponsel Android,” 2015.

[2] G. Chitranshi and M. Gaur, "Using android mobile as a universal remote control," International Journal of Engineering Research and Development, vol. 4, no. 6, pp. 89-92, 2012.

[3] Y. Fauzan, "Rancang Bangun Perangkat Wireless Untuk Projector Konvensional," Universitas Komputer Indonesia, 2016.

[4] A. Irfan Yusuf, "Rancang Bangun Sistem Komunikasi Tanpa Kabel pada Printer berbasis Bluetooth dan Wifi," Universitas Komputer Indonesia, 2014.

[5] P. Kumar and P. Kumar, "Arduino based wireless intrusion detection using IR sensor and GSM,” International Journal of Computer Science and Mobile Computing, vol. 2, no. 5, pp. 417-424, 2013.

[6] T. A. Latif and S. T. Helman Muhammad, "Pengendalian Proyektor LCD dari Jarak Jauh dengan Wifi dan Raspberry pi,” Universitas Muhammadiyah Surakarta, 2017.

[7] S. M. Nejakar, "Wireless Infrared Remote Controller for Multiple Home Appliances," International Journal of Electrical and Electronics Research, vol. 2, no. 1, pp. 25-35, 2014. 